\title{
Systematic review and meta-analysis of risk factor for postoperative delirium following spinal surgery
}

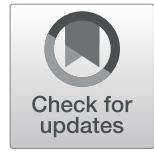

Hao Jie Zhang, Xue Hai Ma, Jin Biao Ye, Cong Zhi Liu and Zhi Yang Zhou*

\begin{abstract}
Background: Postoperative delirium is a common psychiatric disorder among patients who undergo spinal surgery. The purpose of current meta-analysis was to assess the potential risk factors related to delirium in spinal surgery.

Methods: We searched the following databases: PubMed, EMBASE, the Cochrane Library, and Web of Science, from inception to July 2020. Two reviewers independently assessed the quality of the included studies using the previously described Newcastle-Ottawa Scale (NOS). We included spinal surgery patients who suffered with delirium or not. Stata 12.0 was used for meta-analysis.

Results: Thirteen trial studies that met our inclusion criteria were incorporated into the meta-analysis. Postoperative delirium was associated with an increase of the duration of hospital stay $(P=0.044)$ and increased perioperative readmission rate $(P=0.013)$ and economic costs $(P=0.002)$. This meta-analysis demonstrates that there were twenty-two risk factors: general characteristic: old age, female patients, history of surgery, diabetes mellitus, hypertension; preoperative data: low hematocrit, low hemoglobin, low albumin, low sodium, depression; operative data: operating time, total blood loss; postoperative data: low sodium, low hemoglobin, low hematocrit, low albumin, fever, low potassium, blood sugar, and visual analog scale (VAS).

Conclusions: Delirium not only prolongs the length of hospital stay, but also increases readmission rate and the economic costs. Several risk factors including old age, female patients, history of surgery, diabetes mellitus, low hematocrit, low hemoglobin, low albumin, low sodium, depression; operative data: operating time, total blood loss, low sodium, low hemoglobin, low hematocrit, low albumin, fever, low potassium, blood sugar, and VAS were significant predictors for postoperative delirium after spinal surgery.
\end{abstract}

Keywords: Delirium, Spinal surgery, Risk factor, Meta-analysis

\section{Background}

Delirium is defined as an acute disorder of attention and cognition and is associated with underlying physiological disorders [1]. Postoperative delirium after spinal surgery was a common complication in older patients. The incidence of postoperative delirium after spinal surgery has

\footnotetext{
* Correspondence: zhouzhiyang6286@sina.com

Department of Orthopedics, Huai An Hospital of Huai An City, No. 161, Zhenhuailou East Road, Huai'an District, Huai'an City, Jiangsu Province 223200, China
}

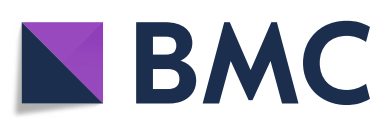

(c) The Author(s). 2020 Open Access This article is licensed under a Creative Commons Attribution 4.0 International License, which permits use, sharing, adaptation, distribution and reproduction in any medium or format, as long as you give appropriate credit to the original author(s) and the source, provide a link to the Creative Commons licence, and indicate if changes were made. The images or other third party material in this article are included in the article's Creative Commons licence, unless indicated otherwise in a credit line to the material. If material is not included in the article's Creative Commons licence and your intended use is not permitted by statutory regulation or exceeds the permitted use, you will need to obtain permission directly from the copyright holder. To view a copy of this licence, visit http://creativecommons.org/licenses/by/4.0/. The Creative Commons Public Domain Dedication waiver (http://creativecommons.org/publicdomain/zero/1.0/) applies to the data made available in this article, unless otherwise stated in a credit line to the data. 18.4 to $40.5 \%$ [2]. Patients with delirious state were associated with a prolonged hospital stay, increased the economic costs, and impaired individual's function and quality of life [3]. Postoperative delirium occurs in many surgeries, including major vascular surgery, hip surgery, and spinal surgery $[4,5]$. However, the mechanism of delirium was unclear. Thus, understanding the risk factor for delirium in spinal patients was important. 
A meta-analysis review by Shi et al. [6] evaluated the risk factor of delirium after spinal surgery. However, it contained some methodological shortcomings; all of the risk factors were not evaluated and with high heterogeneity. Not only did these studies have these limitations, but also they did not individually separate preoperative hemoglobin level and postoperative hemoglobin level. Considering all these issues and new evidence emerging, it is impossible to give clear advice on the risk factor of the delirium after spinal surgery. Thus, we undertook a further metaanalysis to identify the risk factors for delirium in spinal surgery patients.

\section{Methods}

This study was designed and reported according to the Preferred Reporting Items for Systematic Reviews and Meta-Analyses (PRISMA) statement [7].

\section{Literature search}

We searched the following electronic databases: PubMed, EMBASE, the Cochrane Library, and Web of Science from inception to July 2020. The search terms were [delirium OR confusion OR transient mental disorder OR dementia OR cognitive disorders] AND [spine OR spinal OR lumbar infusion] AND [surgery OR operation]. We also searched the references of the included studies and recent reviews or meta-analysis.

\section{Study selection}

Inclusion criteria were as follows: (i) patients who had undergone spinal surgery; (ii) the studies' design was observational or cohort study; (iii) delirium and controls diagnosed by delirium assessment tool; (iv) studies reporting adequate data for pooling for the analysis; (v) studies published in Chinese or English. The exclusion criteria were as follows: (i) review articles, letter, or comments; (ii) studies without available data for statistics;

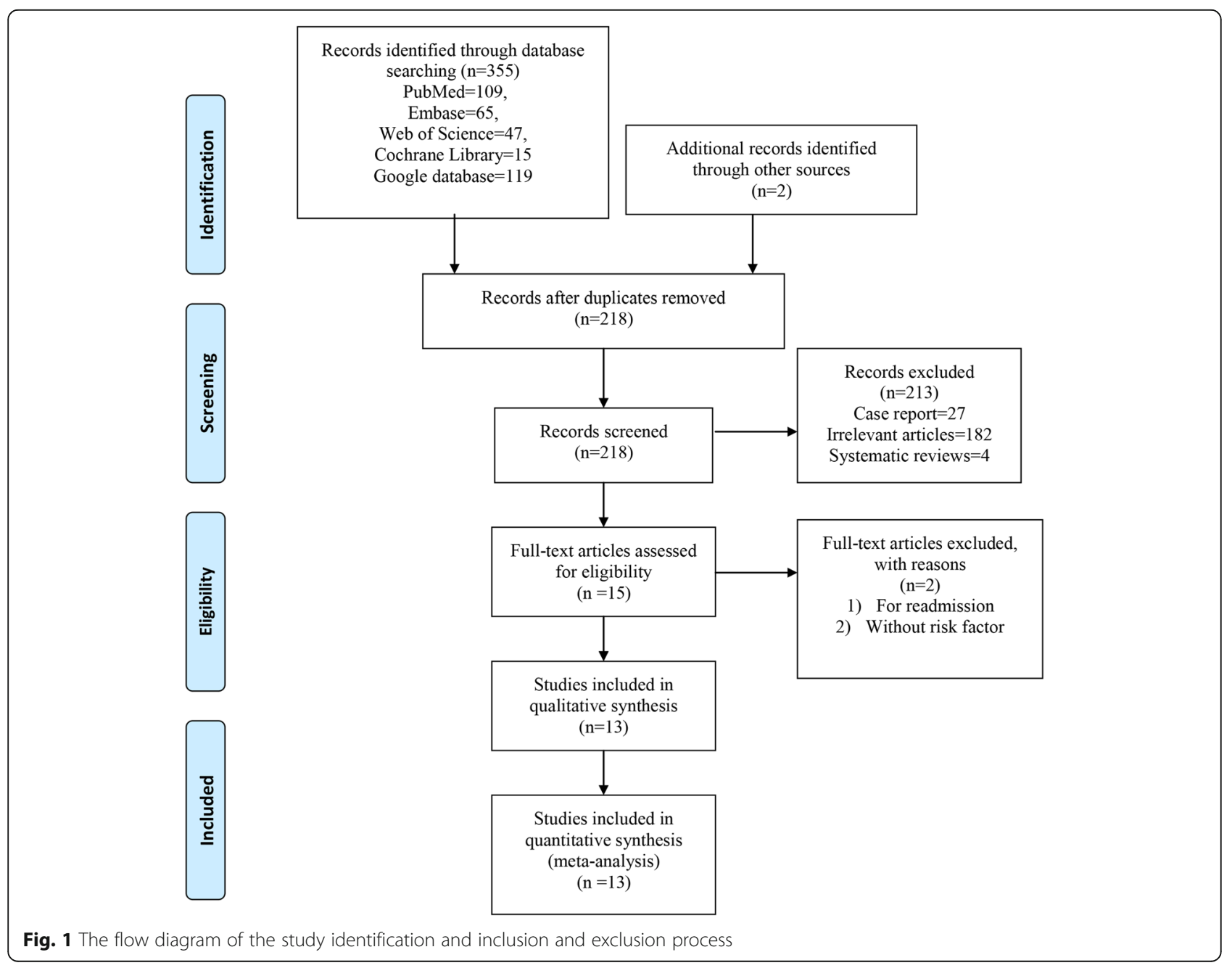


(iii) there were no diagnostic criteria for delirium after spinal surgery.

\section{Data extraction}

All the data were extracted by two authors from all eligible studies (Hao-Jie Zhang and Xue-Hai Ma). The following variables were extracted from each study: first author's name, publication year, country, study design, study setting, sample size, age, sex ratio, criteria for delirium, screening frequency, study quality score. Any disagreement was resolved by discussion or consulted from a senior reviewer to reach a consensus.

\section{Quality assessment}

Two reviewers (Jin-Biao Ye and Cong-Zhi Liu) independently assessed the quality of the included studies using the previously described Newcastle-Ottawa Scale (NOS) [8]. A total of three items were included: (1) patient selection, (2) comparability of the two study arms, and (3) assessment of the outcomes. Studies were classified according to quality: high quality (7-9), moderate quality (5-6), poor quality (0-4).

\section{Data synthesis and analysis}

All statistical analyses were conducted in Stata 12.0 (Stata Corp., College Station, TX). We estimated the pooled risk ratios (RRs) for the binary variable and weighted mean differences (WMD) for the continuous data. We used random effects model or fixed effects model according to the heterogeneity between the studies. We assessed statistical heterogeneity using the $I$ square $\left(I^{2}\right)$ values $\left(I^{2}>50 \%\right.$ was considered to imply statistical heterogeneity).

\section{Results}

First, we initially yielded 355 relevant studies from electronic databases and 2 additional records through other

Table 1 The general characteristic of the included studies

\begin{tabular}{|c|c|c|c|c|c|c|c|c|c|}
\hline Reference & Country & $\begin{array}{l}\text { Study } \\
\text { design }\end{array}$ & Study setting & $\begin{array}{l}\text { Sample } \\
\text { size }\end{array}$ & $\begin{array}{l}\text { Age } \\
\text { (year) }\end{array}$ & $\begin{array}{l}\text { Sex } \\
\text { ratio } \\
(\mathrm{M}: \mathrm{F})\end{array}$ & $\begin{array}{l}\text { Criteria for } \\
\text { delirium }\end{array}$ & $\begin{array}{l}\text { Screening } \\
\text { frequency } \\
\text { (h) }\end{array}$ & $\begin{array}{l}\text { Study } \\
\text { quality } \\
\text { score }\end{array}$ \\
\hline $\begin{array}{l}\text { Adogwa } \\
\text { et al. [9] }\end{array}$ & USA & $\mathrm{RCS}$ & Correction of adult degenerative scoliosis & 82 & 71.8 & NS & CAM & n.s & 7 \\
\hline $\begin{array}{l}\text { Brown } \\
\text { et al. [10] }\end{array}$ & USA & Cohort & $\begin{array}{l}\text { Lumbar spine surgery, posterior cervical spine } \\
\text { surgery, or anterior cervical spine }\end{array}$ & 89 & 74 & $47 / 42$ & CAM & $24 \mathrm{~h}$ & 9 \\
\hline $\begin{array}{l}\text { Elsamadicy } \\
\text { et al. [11] }\end{array}$ & USA & & Elective spine surgery & & & & NS & & 7 \\
\hline $\begin{array}{l}\text { Fineberg } \\
\text { et al. [12] }\end{array}$ & USA & $\mathrm{RCS}$ & Lumbar spine & 578,457 & & & ICD-9-CM & NS & 6 \\
\hline $\begin{array}{l}\text { Gao et al. } \\
{[13]}\end{array}$ & China & $\mathrm{RCS}$ & Cervical, thoracic, lumbar, and sacral spine & 549 & 48.2 & & DOS, DSM-IV & $24 \mathrm{~h}$ & 6 \\
\hline $\begin{array}{l}\text { Jiang et al. } \\
{[14]}\end{array}$ & China & $\mathrm{RCS}$ & $\begin{array}{l}\text { Fusion, decompressive laminectomy and } \\
\text { discectomy of the lumbar spine, and anterior } \\
\text { cervical discectomy and fusion, laminoplasty, and } \\
\text { foraminotomy of the cervical spine }\end{array}$ & 451 & 65.1 & $\begin{array}{l}226 / \\
225\end{array}$ & NS & NS & 6 \\
\hline $\begin{array}{l}\text { Kawaguchi } \\
\text { et al. [15] }\end{array}$ & Japan & $\mathrm{RCS}$ & $\begin{array}{l}\text { Cervical spine, cervico-thoracic spine in the thoracic } \\
\text { spine, in the thoraco-lumbar spine, in the lumbar } \\
\text { spine, and cervical and lumbar spine }\end{array}$ & 341 & 59.2 & $\begin{array}{l}186 / \\
155\end{array}$ & CAM & NS & 6 \\
\hline $\begin{array}{l}\text { Kobayashi } \\
\text { et al. [16] }\end{array}$ & Japan & $\mathrm{RCS}$ & Cervical, thoracic, and lumbar spine & 262 & 82.7 & $\begin{array}{l}122 / \\
140\end{array}$ & $\begin{array}{l}\text { CONFUCIUS } \\
\text { stepped } \\
\text { wedge } \\
\text { protocol }\end{array}$ & NS & 8 \\
\hline $\begin{array}{l}\text { Lee et al. } \\
\text { [17] }\end{array}$ & Korea & $\mathrm{RCS}$ & Anterior fusion and posterolateral fusion & 81 & 73.5 & $28 / 53$ & DSM-IV, CAM & NS & 8 \\
\hline $\begin{array}{l}\text { Seo et al. } \\
{[18]}\end{array}$ & Korea & $\mathrm{RCS}$ & $\begin{array}{l}\text { Operation, decompressive laminectomy and } \\
\text { discectomy of the lumbar spine, anterior cervical } \\
\text { discectomy and fusion, laminoplasty and } \\
\text { foraminotomy of the cervical spine }\end{array}$ & 70 & 70.1 & $32 / 38$ & DSM-5 & NS & 9 \\
\hline $\begin{array}{l}\text { Ushida } \\
\text { et al. [19] }\end{array}$ & Japan & $\mathrm{RCS}$ & Cervical myelopathy & 81 & NS & $41 / 41$ & NS & NS & 8 \\
\hline Li et al. [20] & China & $\mathrm{RCS}$ & Spinal surgery & 116 & 75.3 & $62 / 54$ & CAM-ICU & $24 \mathrm{~h}$ & 6 \\
\hline Adogwa & USA & $\mathrm{RCS}$ & Spinal deformity surgery & 82 & 74.7 & $64 / 18$ & CAM-ICU & NS & 8 \\
\hline
\end{tabular}




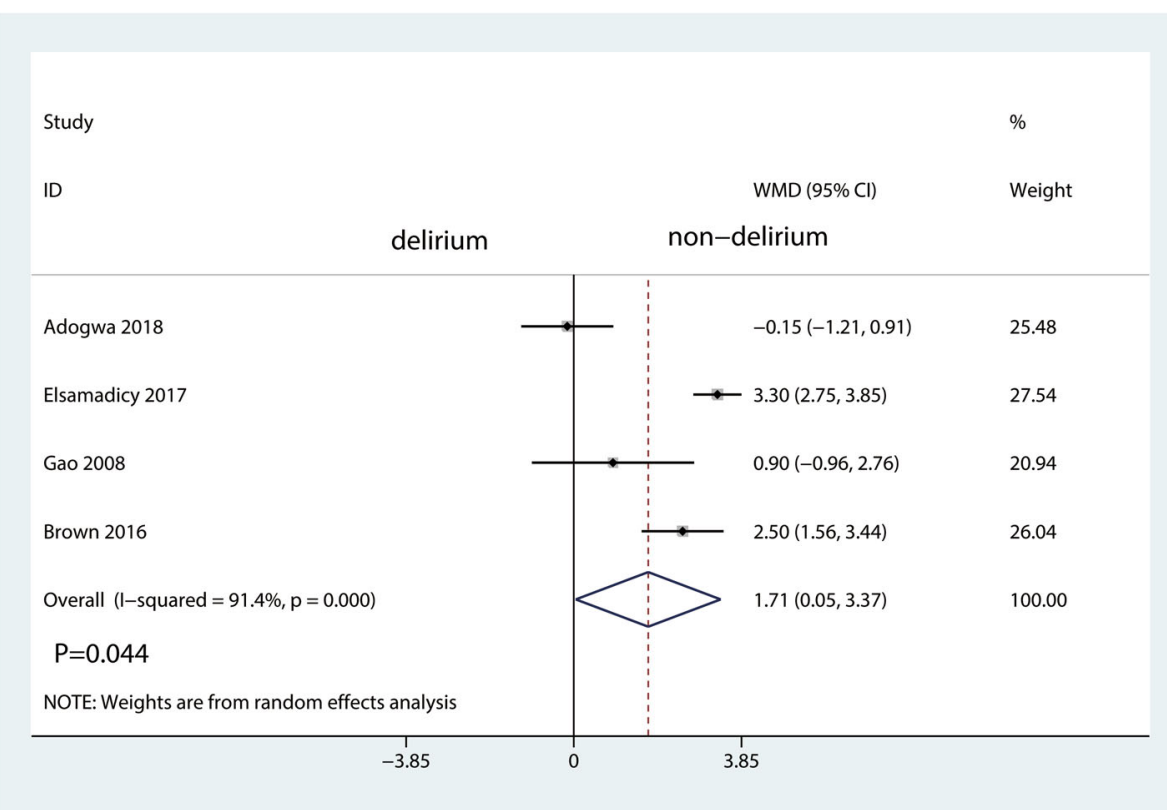

Fig. 2 The forest plot for duration of hospital stay in the delirium group versus the non-delirium group

sources, of which 137 publications were excluded because they were duplications. After reading the title and abstract of these 218 papers, 203 papers were excluded as they did not fulfill the inclusion criteria. Then, 2 studies were excluded after reading the full-text; one study was not interested in delirium but for readmission; another study did not include risk factor of delirium.
Ultimately, thirteen trials [9-21] met the inclusion criteria. The flow diagram of study selection is shown in Fig. 1.

\section{Study characteristics and quality assessment}

General characteristics of the included studies are presented in Table 1. The publication year of the 24 studies

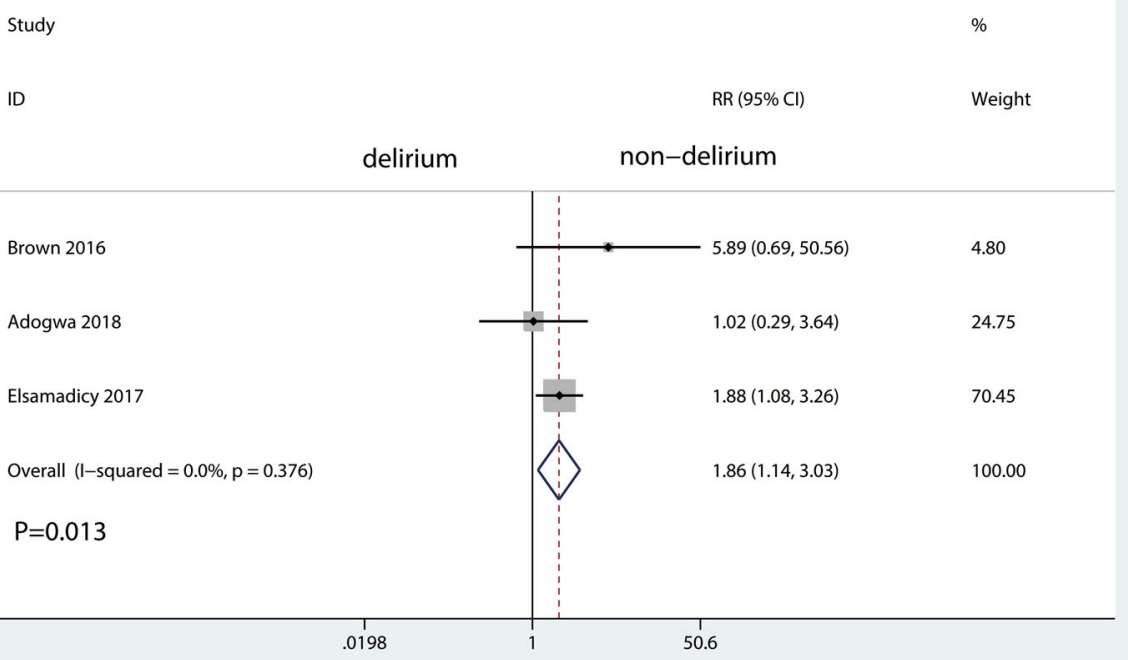

Fig. 3 The forest plot for readmission rate in the delirium group versus the non-delirium group 
ranged from 2004 to 2018 . Four studies were published in the USA, three studies originated from China, three originated from Japan, and the rest were from Korea. Study quality score ranged from 6 to 9 .

\section{Results of meta-analysis}

There was also a statistically significant association of delirium with increased duration of hospital stay $(\mathrm{MD}=1.71$ (95\% CI 0.05 to 3.37) days; $P=0.044$; Fig. 2) and increased perioperative readmission rate (RR $1.86,95 \%$ CI 1.14 to 3.03, $P=0.013$, Fig. 3) and economic costs $(\mathrm{MD}=$ 16166.37 (95\% CI 5988.62 to $26,344.11) P=0.002$, Fig. 4).

\section{Risk factors}

Patients who developed delirium were significantly older (age > 65, RR $=6.13$ (95\% CI 5.75, 6.54), $P=0.000$; age > $70, \mathrm{RR}=18.23$ (95\% CI 3.13, 107.34), $P=0.001$, mean age, $\mathrm{WMD}=1.34(95 \%$ CI 0.34, 2.33), $P=0.009$, Table 2$)$. Sex was also associated with delirium in univariable analysis or meta-analysis (female patients, $\mathrm{RR}=1.21$ (95\% CI 1.15, 1.28 , Table 2)).

Surgical history was also a risk factor of delirium $(\mathrm{RR}=$ 2.22; 95\% CI 1.47, 3.34; Table 2). Diabetes mellitus and hypertension were also risk factors of delirium $(R R=2.80$, $95 \%$ CI 1.15, 6.79), $P=0.023$; RR $=2.01,95 \%$ CI 1.04 ,
3.88, $P=0.038$, Table 2). Low hematocrit, low hemoglobin, low albumin, and low sodium were the risk factors of delirium $(P=0.011, P=0.017, P=0.003$, and $P$ $=0.019$, Table 2). We also found that depression was the risk factor of delirium of patients undergoing spinal surgery $(\mathrm{RR}=2.02 ; 95 \% \mathrm{CI} 1.00,4.06 ; P=0.049$; Table 2$)$.

\section{Intraoperative data}

For intraoperative data, we revealed that operating time $(\mathrm{WMD}=29.42 ; 95 \%$ CI 1.12, 57.72; $P=0.042$, Table 2$)$ and total blood loss (WMD $=116.77 ; 95 \%$ CI 93.66, 139.88; $P=0.000$; Table 2) were risk factor of delirium.

\section{Postoperative data}

Based on the combined RRs or WMDs, we identified the following risk factors: low sodium (WMD $=-3.05$; 95\% CI $-5.47,-0.63 ; P=0.014$; Table 2), low hemoglobin $(\mathrm{WMD}=-0.76 ; 95 \% \mathrm{CI}-1.24,-0.29 ; P=0.002$; Table 2), low hematocrit (WMD $=-2.53$; 95\% CI -3.59 , 1.47; $P=0.000$; Table 2), fever $(\mathrm{WMD}=4.52 ; 95 \% \mathrm{CI}$ 2.94, 6.95; $P=0.000$; Table 2), low potassium (WMD = - 3.05; 95\% CI - 5.47, $-0.63 ; P=0.014$; Table 2), blood sugar $(\mathrm{WMD}=1.00 ; 95 \%$ CI 1.00, 1.96; $P=0.041$; Table 2 ), and VAS (WMD $=0.98$; 95\% CI $0.11,1.85, P=0.027$; Table 2).

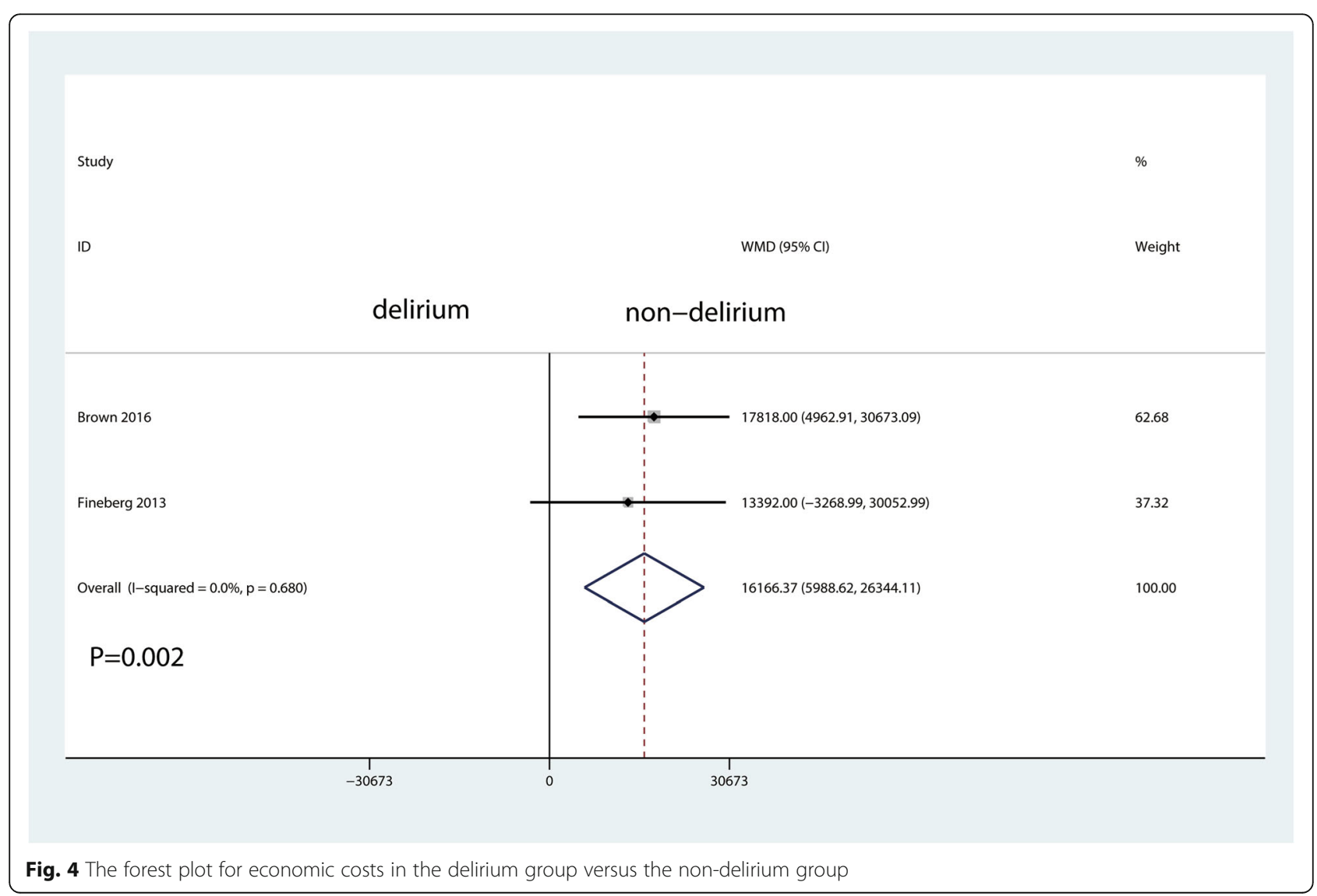


Table 2 Meta-analysis of risk factors for postoperative delirium in older spinal surgical patients

\begin{tabular}{|c|c|c|c|c|c|}
\hline Risk factor & Studies & Statistically methods & RR or WMD with $95 \%$ Cis & $I^{2}(\%)$ & $P$ value \\
\hline \multicolumn{6}{|l|}{ Preoperative } \\
\hline Age $>65$ years & 2 & IV, fixed & $6.13(5.75,6.54)$ & 0.0 & 0.000 \\
\hline Age $>70$ years & 3 & IV, random & $18.23(3.13,107.34)$ & 48.4 & 0.001 \\
\hline Sex (\% female) & 8 & IV, fixed & $1.21(1.15,1.28)$ & 0.001 & 0.000 \\
\hline Mean age & 6 & IV, fixed & $1.34(0.34,2.33)$ & 6.0 & 0.009 \\
\hline Number of medication & 3 & IV, random & $0.92(-0.05,1.88)$ & 77.5 & 0.063 \\
\hline Surgical history & 6 & IV, fixed & $2.22(1.47,3.34)$ & 0.0 & 0.000 \\
\hline Diabetes mellitus & 7 & IV, random & $2.80(1.15,6.79)$ & 70.6 & 0.023 \\
\hline Cerebral vascular diseases & 3 & IV, fixed & $3.18(1.27,7.79)$ & 15.7 & 0.014 \\
\hline Low hematocrit (\%) & 3 & IV, fixed & $-1.66(-2.94,-0.38)$ & 0.0 & 0.011 \\
\hline Low hemoglobin (g/L) & 4 & IV, fixed & $-0.41(-0.75,-0.07)$ & 0.0 & 0.017 \\
\hline Low albumin (g/dL) & 2 & IV, fixed & $-0.30(-0.50,-0.11)$ & 18.7 & 0.003 \\
\hline Low sodium & 4 & IV, random & $-1.81(-3.33,-0.30)$ & 77.8 & 0.019 \\
\hline Low potassium & 2 & IV, random & $0.00(-0.28,0.28)$ & 45.4 & 0.996 \\
\hline Blood sugar & 2 & IV, random & $0.13(-0.52,0.78)$ & 33.4 & 0.698 \\
\hline Hypertension & 7 & IV, random & $2.01(1.04,3.88)$ & 58.3 & 0.038 \\
\hline Depression & 2 & IV, fixed & $2.02(1.00,4.06)$ & 0.0 & 0.049 \\
\hline \multicolumn{6}{|l|}{ Intraoperative } \\
\hline Operating time & 9 & IV, random & $29.42(1.12,57.72)$ & 87.9 & 0.042 \\
\hline Total blood loss & 8 & IV, fixed & $116.77(93.66,139.88)$ & 14.9 & 0.000 \\
\hline Fusion level & 2 & IV, random & $0.35(-0.72,1.42)$ & 52.3 & 0.524 \\
\hline Intravenous fluids & 4 & IV, random & $231.24(-137.99,600.47)$ & 68.9 & 0.220 \\
\hline \multicolumn{6}{|l|}{ Postoperative data } \\
\hline Low sodium (mEq/L) & 4 & IV, random & $-3.05(-5.47,-0.63)$ & 89.7 & 0.014 \\
\hline Low hemoglobin (g/L) & 6 & IV, random & $-0.76(-1.24,-0.29)$ & 82.5 & 0.002 \\
\hline Low hematocrit (\%) & 3 & IV, fixed & $-2.53(-3.59,-1.47)$ & 0.0 & 0.000 \\
\hline Low albumin (g/dL) & 2 & IV, fixed & $-0.10(-0.27,0.07)$ & 0.0 & 0.245 \\
\hline Fever & 2 & IV, fixed & $4.52(2.94,6.95)$ & 0.0 & 0.000 \\
\hline Low potassium & 4 & IV, random & $-3.05(-5.47,-0.63)$ & 89.7 & 0.014 \\
\hline Blood sugar & 1 & IV, fixed & $1.00(1.00,1.96)$ & 0.0 & 0.041 \\
\hline VAS & 2 & IV, random & $0.98(0.11,1.85)$ & 55.4 & 0.027 \\
\hline
\end{tabular}

\section{Discussion}

Thirteen studies met the inclusion criteria and investigated risk factors for postoperative delirium in older people undergoing spinal surgery. Results in this metaanalysis suggested the overall prevalence of postoperative delirium was $11.5 \%$. The prevalence of delirium ranged from 3.8 to $40.4 \%$ in the included studies.

Postoperative delirium was associated with increased duration of hospital stay, readmission rate, and the economic costs. Scholz et al. [22] found that patients with postoperative delirium had a significantly increased duration of hospital stay compared with those without delirium.
A better understanding of risk factors for delirium may allow stratification of patients before surgery, enabling targeting of interventions and healthcare resources, for example the Comprehensive Geriatric Assessment, a proven multidisciplinary intervention that can improve outcomes in patients with postoperative delirium [23].

This meta-analysis demonstrates that twenty-two risk factors: general characteristic: old age, female patients, history of surgery, diabetes mellitus, hypertension; preoperative data: low hematocrit, low hemoglobin, low albumin, low sodium, depression; operative data: operating time, total blood loss; postoperative data: low sodium, low hemoglobin, low 
hematocrit, low albumin, fever, low potassium, blood sugar, and VAS.

One of the most important risk factors was advanced age, especially patient over 70 years old are more likely to experience postoperative delirium than those relatively young. Shi et al. [6] revealed that age $>65$ years was the risk factor for delirium. We further analyze that the age $>70$ was more likely to subject to delirium. Zhu et al. [24] conducted a meta-analysis and found that old age, age $>70$ years, was a risk factor of the major head neck cancer surgery. This may be due to the fact that elderly patients were more likely influenced by agerelated physical and psychical changes, such as poor organ compensative capacity, reduced body adaptability, and declined adjustment ability. Watt et al. [25] found that incidence of postoperative delirium was $18.4 \%$ in elective surgery. What's more, they revealed that psychotropic medication use and smoking status were two risk factors for delirium in elective surgery patients.

Patients who developed postoperative delirium were more often females. Our results were opposite of previous meta-analysis. Zhu et al. [24] deemed that women could deal with postoperative psychological stress better than male and thus was associated with less delirium. Shi et al. [6] identified female patients were associated with more delirium than male patients. Scholz et al. [22] found that sex was not associated with delirium in univariable analysis or meta-analysis. Current meta-analysis also found that hypotension was the risk factor of delirium after spinal surgery. Scholz et al. [22] found that intraoperative hypotension and perioperative blood transfusion were the risk factors of delirium.

Low hemoglobin and low hematocrit may reduce oxygen supply to the brain and thus causing delirium. Marcantonio et al. [26] also suggest that the postoperative levels of hematocrit should be kept at 30\% or higher through appropriate transfusion in order to prevent postoperative delirium. Meanwhile, the low preoperative levels of albumin seem to indicate poor nutritional condition before surgery and after surgery, like the case with gastric ulcer as comorbidity [17].

There were several limitations in this meta-analysis: (1) heterogeneity bias within the selected studies. In particular, the review was susceptible to heterogeneity owing to the inclusion of different spinal surgery (cervical spondylosis, spinal scoliosis, and lumbar degenerative disease). (2) Another limitation was that only articles published in English and Chinese were included, yet most of the studies were undertaken in non-English-speaking countries. We also did not include unpublished papers and thus may have selection bias. (3) All studies assessed delirium from 3 to 7 days after surgery. Differences in duration of follow-up may have introduced bias, but the majority used 5 days and consistently demonstrated the highest rate of delirium in the first 3 days.

\section{Conclusion}

Delirium not only prolongs the length of hospital stay, but also increases readmission rate and the economic costs. Several risk factors including old age, female patients, history of surgery, diabetes mellitus, low hematocrit, low hemoglobin, low albumin, low sodium, depression; operative data: operating time, total blood loss, low sodium, low hemoglobin, low hematocrit, low albumin, fever, low potassium, blood sugar, and VAS were significant predictors for postoperative delirium after spinal surgery. Early identification of these factors is warranted for improving patient outcomes.

\section{Abbreviations \\ CNKI: China National Knowledge Infrastructure; RRs: Risk ratios; Cls: Confidence intervals; WMD: Weighted mean difference; PRIS MA: Preferred Reporting Items for Systematic Reviews and Meta-Analyses; NOS: Newcastle-Ottawa Scale; VAS: Visual analog scale}

\section{Acknowledgements}

We would thank Xue Hai Ma and Jin Biao Ye for independent assessment of the quality of the included studies.

\section{Available of data and materials}

All data are fully available without restriction.

\section{Authors' contributions}

HJZ and XHM conceived of the design of the study. JBY participated in the literature search, study selection, data extraction, and quality assessment. CZL and ZYZ performed statistical analysis. All authors read and approved the final manuscript.

\section{Funding}

Not applicable.

\section{Ethics approval and consent to participate}

This paper does not contain any studies with human participants or animals performed by any of the authors.

\section{Consent for publication}

Not applicable.

\section{Competing interests}

The authors declare that they have no competing interests.

Received: 4 September 2020 Accepted: 20 October 2020

Published online: 05 November 2020

\section{References}

1. Oh ES, Fong TG, Hshieh TT, Inouye SK. Delirium in older persons: advances in diagnosis and treatment. Jama. 2017;318(12):1161-74.

2. Watt J, Tricco AC, Talbot-Hamon C, Pham B, Rios P, Grudniewicz A, Wong C, Sinclair D, Straus SE. Identifying older adults at risk of delirium following elective surgery: a systematic review and meta-analysis. J Gen Intern Med. 2018.

3. Hamilton GM, Wheeler K, Di Michele J, Lalu MM, Mclsaac DI. A systematic review and meta-analysis examining the impact of incident postoperative delirium on mortality. Anesthesiology. 2017;127(1):78-88.

4. Aitken SJ, Blyth FM, Naganathan V. Incidence, prognostic factors and impact of postoperative delirium after major vascular surgery: a meta-analysis and systematic review. Vasc Med. 2017;22(5):387-97.

5. Smith To, Cooper A, Peryer G, Griffiths R, Fox C, Cross J: Factors predicting incidence of post-operative delirium in older people following hip fracture surgery: a systematic review and meta-analysis. Int J Geriatr Psychiatry 2017, 32(4):386-396.

6. Shi C, Yang C, Gao R, Yuan W. Risk factors for delirium after spinal surgery: a meta-analysis. World Neurosurg. 2015;84(5):1466-72. 
7. Liberati A, Altman DG, Tetzlaff J, Mulrow C, Gotzsche PC, loannidis JP, Clarke M, Devereaux PJ, Kleijnen J, Moher D. The PRISMA statement for reporting systematic reviews and meta-analyses of studies that evaluate healthcare interventions: explanation and elaboration. BMJ. 2009;339:b2700.

8. Stang A. Critical evaluation of the Newcastle-Ottawa scale for the assessment of the quality of nonrandomized studies in meta-analyses. Eur J Epidemiol. 2010;25(9):603-5.

9. Adogwa O, Elsamadicy AA, Vuong VD, Fialkoff J, Cheng J, Karikari IO, Bagley CA. Association between baseline cognitive impairment and postoperative delirium in elderly patients undergoing surgery for adult spinal deformity. J Neurosurg Spine. 2018;28(1):103-8.

10. Brown CH, LaFlam A, Max L, Wyrobek J, Neufeld K, Kebaish KM, Cohen DB, Walston JD, Hogue CW, Riley LH. Delirium after spine surgery in older adults: incidence, risk factors, and outcomes. J Am Geriatr Soc. 2016;64(10): 2101-8.

11. Elsamadicy AA, Adogwa O, Lydon E, Sergesketter A, Kaakati R, Mehta Al, Vasquez RA, Cheng J, Bagley CA, Karikari IO. Depression as an independent predictor of postoperative delirium in spine deformity patients undergoing elective spine surgery. J Neurosurg Spine. 2017;27(2):209-14.

12. Fineberg SJ, Nandyala SV, Marquez-Lara A, Oglesby M, Patel AA, Singh K. Incidence and risk factors for postoperative delirium after lumbar spine surgery. Spine. 2013;38(20):1790-6.

13. Gao R, Yang ZZ, Li M, Shi ZC, Fu Q. Probable risk factors for postoperative delirium in patients undergoing spinal surgery. Eur Spine J. 2008;17(11): $1531-7$.

14. Jiang $X$, Chen D, Lou Y, Li Z. Risk factors for postoperative delirium after spine surgery in middle- and old-aged patients. Aging Clin Exp Res. 2017; 29(5):1039-44

15. Kawaguchi $Y$, Kanamori M, Ishihara H, Abe Y, Nobukiyo M, Sigeta T, Hori T, Kimura T. Postoperative delirium in spine surgery. Spine J. 2006;6(2):164-9.

16. Kobayashi K, Imagama S, Ando K, Ishiguro N, Yamashita M, Eguchi Y, Matsumoto M, Ishii K, Hikata T, Seki S, et al. Risk factors for delirium after spine surgery in extremely elderly patients aged 80 years or older and review of the literature: Japan Association of Spine Surgeons with ambition multicenter study. Global Spine J. 2017:7(6):560-6.

17. Lee JK, Park YS. Delirium after spinal surgery in Korean population. Spine. 2010;35(18):1729-32.

18. Seo JS, Park SW, Lee YS, Chung C, Kim YB. Risk factors for delirium after spine surgery in elderly patients. J Korean Neurosurg Soc. 2014;56(1):28-33.

19. Ushida T, Yokoyama T, Kishida Y, Hosokawa M, Taniguchi S, Inoue S, Takemasa R, Suetomi K, Arai YC, McLaughlin M, et al. Incidence and risk factors of postoperative delirium in cervical spine surgery. Spine. 2009; 34(23):2500-4.

20. Li H, Li CD, Yi XD, Liu H, Liu XY. Analysis of risk factors for delirium in the elderly patients after spinal operation. J Peking University (Health Sciences). 2012;44(6):847-50

21. Adogwa O, Elsamadicy AA, Lydon E, Vuong VD, Cheng J, Karikari IO, Bagley CA. The prevalence of undiagnosed pre-surgical cognitive impairment and its post-surgical clinical impact in elderly patients undergoing surgery for adult spinal deformity. J Spine Surg. 2017;3(3):358-63.

22. Scholz AF, Oldroyd C, McCarthy K, Quinn TJ, Hewitt J. Systematic review and meta-analysis of risk factors for postoperative delirium among older patients undergoing gastrointestinal surgery. Br J Surg. 2016;103(2):e21-8.

23. Welsh TJ, Gordon AL, Gladman JR. Comprehensive geriatric assessment--a guide for the non-specialist. Int J Clin Pract. 2014;68(3):290-3.

24. Zhu Y, Wang G, Liu S, Zhou S, Lian Y, Zhang C, Yang W. Risk factors for postoperative delirium in patients undergoing major head and neck cancer surgery: a meta-analysis. Jpn J Clin Oncol. 2017;47(6):505-11.

25. Watt J, Tricco AC, Talbot-Hamon C, Pham B, Rios P, Grudniewicz A, Wong C, Sinclair D, Straus SE. Identifying older adults at risk of delirium following elective surgery: a systematic review and meta-analysis. J Gen Intern Med. 2018;33(4):500-9.

26. Marcantonio ER, Goldman L, Orav EJ, Cook EF, Lee TH. The association of intraoperative factors with the development of postoperative delirium. Am J Med. 1998;105(5):380-4.

\section{Publisher's Note}

Springer Nature remains neutral with regard to jurisdictional claims in published maps and institutional affiliations.

Ready to submit your research? Choose BMC and benefit from:

- fast, convenient online submission

- thorough peer review by experienced researchers in your field

- rapid publication on acceptance

- support for research data, including large and complex data types

- gold Open Access which fosters wider collaboration and increased citations

- maximum visibility for your research: over $100 \mathrm{M}$ website views per year

At BMC, research is always in progress.

Learn more biomedcentral.com/submissions 